\title{
AUTHENTICATION OF HAZELNUT OIL BY PORTABLE FT-NIR, FT-MIR AND RAMAN SPECTROMETERS COMBINED WITH MULTIVARIATE DATA ANALYSIS
}

\author{
Ahmed Menevseoglu' ${ }^{1 *}$, Didem Peren Aykas ${ }^{2}$ \\ ${ }^{1}$ Department of Food Engineering, Faculty of Engineering and Natural Sciences, Gumushane University, \\ Gumushane, Turkey \\ ${ }^{2}$ Department of Food Engineering, Faculty of Engineering, Adnan Menderes University, Aydin, Turkey \\ Received / Geliş: 04.08.2021; Accepted / Kabul: 04.11.2021; Published online / Online bask1: 22.12.2021 \\ Menevseoglu, A., Aykas, D.P. (2022). Authentication of harelnut oil by portable FT-NIR, FT-MIR and Raman \\ spectrometers combined with multivariate data analysis. GIDA (2022) 47 (1) 1-14 doi: 10.15237/gida.GD21113
}

Menevseoglu, A., Aykas, D.P. (2022). Findık yağının FT-NIR, FT-MIR ve Raman spektrometreleri ile birlikte çok bileşenli veri analizleri kullanılarak doğrulanması. GIDA (2022) 47 (1) 1-14 doi: $10.15237 /$ gida.GD21113

\begin{abstract}
This research studied the authentication of hazelnut oil by portable FT-NIR, FT-MIR, and Raman spectrometers. Hazelnut oils were adulterated with vegetable oils at various concentrations $(0-25 \%)(\mathrm{w} / \mathrm{w})$. Collected spectra were analyzed using Principal Component Analysis (PCA) and Soft Independent Modelling of Class Analogy (SIMCA) to generate classification models to authenticate pure hazelnut oil and Partial Least Squares Regression (PLSR) to predict the fatty acids and adulterant levels. For confirmation, oil's fatty acid profile was determined by gas chromatography. In all three instruments, SIMCA provided distinct clusters for pure and adulterated samples with interclass distance (ICD) $>3$. All instruments showed excellent performance in predicting fatty acids and adulteration levels with $r_{\mathrm{val}}>0.93$ and standard error prediction $(\mathrm{SEP})<1.75 \%$. Specifically, the FT-MIR unit provided the best performances. Still, all the units can be used as an alternative to traditional methods. These units showed great potential for in-situ surveillance to detect hazelnut oil adulterations.
\end{abstract}

Keywords: Portable devices, FT-NIR, FT-MIR, Raman, adulteration, hazelnut oil

\section{FINDIK YAĞININ FT-NIR, FT-MIR VE RAMAN SPEKTROMETRELERİ İLE BİRLİKTE ÇOK BİLEŞENLİ VERİ ANALİZLERİ KULLANILARAK DOĞRULANMASI}

\section{ÖZ}

$\mathrm{Bu}$ araştırma findık yağının taşınabilir FT-NIR, FT-MIR ve Raman spektrometreleri ile tağşişlerinin belirlenmesi üzerinedir. Fındık yağları değişik konsantrasyonlardaki (0-25\%) (w/w) bitkisel yağlar ile karıştırılmıştır. Toplanan spektralarin Temel Bileşen Analizi (PCA) ve Sınıf Analojisinin Yumuşak Bağımsız Modellenmesi (SIMCA) ile saf findık yağı sınıflandırma modelleri oluşturulmuştur. Yağ asitleri ve tağşiş seviyesi Kısmi En Küçük Kareler Regresyonu (PLSR) kullanılarak belirlenmiştir. Sonuçların doğrulanması için gaz kromatografisi kullanılarak yağların yağ asidi profilleri belirlenmiştir.

*Corresponding author / Yazışmalardan sorumlu yazar:

$\square$ : amenevseoglu@gumushane.edu.tr (0: (+90) 4562331849

Ahmed Menevseoglu ORCID ID: 0000-0003-2454-7898

Didem Peren Aykas ORCID ID: 0000-0002-5500-0441 
Her üç cihazda da SIMCA, saf ve tağşiş edilmiş örneklerin gruplarının sınıflar arası mesafe si (ICD) üçten büyük olarak bulunmuştur. Tüm cihazlar, yağ asidi ve tağşsiş miktarlarının belirlenmesinde yüksek performans göstermiştir, $\mathrm{r}_{\mathrm{val}}>0.93$ ve standart hata tahmini (SEP) $<1.75 \%$. Özellikle, FT-MIR cihazı en iyi performansı göstermiştir. Yine de, tüm cihazlar geleneksel yöntemlere alternatif olarak kullanılabilir. Bu cihazlar, fındık yağı tağşişinin yerinde belirlenmesi icin yüksek bir potansiyel göstermiştir.

Anahtar kelimeler: Taşınabilir cihazlar, FT-NIR, FT-MIR, Raman, tağşşş, findık yağı

\section{INTRODUCTION}

Hazelnut is one of the most popular tree nuts in the world. The largest hazelnut producer, Turkey, had an annual production of 776,000 tons $(69 \%)$ in 2019, followed by Italy with 98,530 t (9\%), Azerbaijan with 53,793 t (5\%), and the U.S. with $39,920 \mathrm{t}(4 \%)$ (FAO, 2020). In recent years, the consumption of hazelnut has been increasing because it is a good source of vitamin $\mathrm{E}$ and oleic acid associated with lowering total and LDL cholesterol levels (Celenk et al., 2020). Hazelnut is widely used in the chocolate industry $(\% 70)$, icecream, pastry, snack, fresh consumption (\%15), and oil industry (5\%) (Guiné and Correia, 2020; MAF - Republic of Turkey Ministry of Agriculture And Forestry, 2020; Platteau et al., 2011). The hazelnut oil industry is growing in Turkey because of the profit margin. Hazelnut oil consists of palmitic (3-7\%), stearic (1.5-3\%), oleic (70-85\%) and linoleic acid (7-20\%). However, either it does not consist of linolenic acid or has a very small amount $(\sim 0.1-0.3 \%)$ (BenitezSánchez et al., 2003; Karabulut et al., 2005; Turan, 2018). It is mostly used as frying, cooking, and salad oil (Şisik Ogras et al., 2018). Until a decade ago, hazelnut oil was used as an adulterant in olive oil due to fatty acid profile similarities and being a cheaper substance (Quintanilla-Casas et al., 2021). However, today, hazelnut oil is recognized as a high commodity valued product in Turkey and it is almost three times expensive than other fixed oils, and it has a similar price range with olive oil. Because hazelnut oil is now a premium oil, it is not feasible to adulterate olive oil with hazelnut oil. Moreover, the demand for hazelnut oil is rising because it consists of mono and polyunsaturated fatty acids; economically motivated adulteration of hazelnut oil is now becoming a concern. Sunflower oil can be used as an adulterant in hazelnut oil because it also has a very low amount of linolenic acid and a high amount of oleic and linoleic acid (Akkaya, 2018) and using only gas chromatography may not detect the adulteration. Similarly, canola oil has a high amount of oleic and linoleic acids, and around $5-7 \%$ of linolenic acid (Zambiazi et al., 2007). Canola oil is also a lot cheaper than hazelnut oil. The use of it as an adulterant in hazelnut oil up to $10 \%$ may not be detected by traditional methods. Thus, a molecular approach is in need to determine the adulteration of hazelnut oil with sunflower and canola oils.

Adulteration of food occurs when high-cost ingredients are replaced with cheaper alternatives that sometimes pose a health threat to humans. For instance, in 2008, the melamine scandal raised in China resulted in 6 infants died and an estimated 52,000 infants were hospitalized (Pei et al., 2011). Oil adulteration in Spain in 1981 caused almost 300 people to die and 20,000 people were affected by toxic oil syndrome (Gelpí et al., 2002). The oil industry is still faced with a high percentage of adulteration incidents. High commodity valued oils such as olive oil and hazelnut oil are generally adulterated with less valued vegetable oils such as cottonseed, sunflower, and canola oil (Ozen and Mauer, 2002). Rapid, low-cost, and easy methods to detect hazelnut oil adulteration are in need since traditional methods such as gas chromatography, liquid chromatography, and nuclear magnetic resonance require high-cost instrumentation, well-trained personnel, and being timeconsuming, which makes these techniques less appealing (Aykas and Menevseoglu, 2021). As an alternative to these techniques in detecting adulterated hazelnut oil, vibrational spectroscopy methods combined with chemometrics can provide fast, sensitive, and reliable information on the oil matrix. These methods could help governing agencies and the food industry as monitoring food safety and quality control (Shotts et al., 2018). Moreover, to maintain companies' 
reputation and avoid any lawsuits, oil manufacturers and importers may need to take rapid actions in case of incidents. Miniaturized spectrometers are now available with the improvements in the micro-electromechanical systems (MEMS), new sensors, detectors, and optical components (Aykas et al., 2020a). Different portable, and handheld vibrational spectroscopy units have become available in the market with the help of these advancements in optical sensor technology (Ayvaz et al., 2016). These units can provide in-situ and real-time assessments to take faster actions for manufacturers and food control agencies with convenience and cost-efficiency (RodriguezSaona et al., 2020). Many portable and handheld units have been evaluated in the literature on different foods, including nuts, oils, honey, yogurt, spices, and fruit juices (Menevseoglu, 2021; Aykas et al., 2020b; Aykas and Menevseoglu, 2021; Aykas et al., 2020c; Ayvaz and Rodriguez-Saona, 2015; Basri et al., 2017; Mcgrath et al., 2020; Menevseoglu et al., 2020; Mossoba et al., 2014; Sun et al., 2020).

On the hazelnut oil adulteration, limited information can be found in the literature. Studies are generally focused on the detection of olive oil adulteration with hazelnut oil because of the similar fatty acid profile (Cercaci et al., 2003; Christy et al., 2004; Mariani et al., 2006; Zabaras and Gordon, 2004), but not hazelnut oil adulteration with fixed oils (Ozen and Mauer, 2002). It is most likely due to regional consumption of hazelnut oil, especially in the eastern Mediterranean, rather than worldwide. Also, as mentioned previously, hazelnut oil is now an expensive product and hazelnut oil adulteration in olive oil does not provide an economic profit.

The aim of this study was to evaluate portable FTNIR, FT-MIR, and Raman spectrometers on the detection of hazelnut oil adulteration with vegetable oils. To the best of our knowledge, no one has evaluated all three types of portable vibrational spectroscopic instruments, namely FT-NIR, FT-MIR, and Raman, on the hazelnut oil adulteration previously.

\section{MATERIALS AND METHODS}

\section{Materials}

Hazelnut oils (36 different commercial products), sunflower oils ( 6 different commercial products), canola oils (6 different commercial products) were purchased from various local markets in Istanbul, Turkey, and Columbus, OH, USA. Sunflower and canola oil were selected because of being cheaper substance to hazelnut oils. Samples were stored at $4{ }^{\circ} \mathrm{C}$ until further analysis to prevent any oxidative changes in the oil. One of the pure hazelnut oils was chosen randomly, and it was adulterated with $5,10,15,20$, and $25 \%$ $(\mathrm{w} / \mathrm{w})$ sunflower oil and canola oil, separately. These levels were selected to imitate realistic and practical applications that generally happened in the adulteration of oils. The levels lower than 10\% are not actually feasible economically, and it limits the use in fraud practices, and too high levels could be easily detected by sensory (Miaw et al., 2018).

\section{Methods}

Near-Infrared spectrometer: The near-infrared spectra of the oil samples were collected by micro-NeoSpectra (Si-Ware Systems, Cairo, Egypt) (Fig 1), a compact Fourier Transform Near-Infrared (FT-NIR) sensor equipped with a single-chip Michelson interferometer with monolithic Opto-electro-mechanical structure with a single uncooled indium-gallium-arsenide (InGaAs) photodetector. A total of $75 \mu$ of oil sample were deposited on the sensor of the unit and the spectra were collected at the range of $7400-3920 \mathrm{~cm}^{-1}$ in absorbance mode and with a $16 \mathrm{~cm}^{-1}$ resolution. Samples were scanned for 15 seconds to increase the signal-to-noise ratio. Spectral data collection was carried out in duplicate.

Mid-Infrared spectrometer: A total of $50 \mu$ l of the oil sample was placed on the IR crystal. The FT-IR 5500 (Agilent Technologies Inc., Santa Clara, CA) (Fig. 1) spectrometer equipped with a temperature controlled 5-bounce $\mathrm{ZnSe}$ crystal set to $65^{\circ} \mathrm{C}$. The spectra were collected at $4 \mathrm{~cm}^{-1}$ resolution over a range from 4000 to $650 \mathrm{~cm}^{-1}$, and an interferogram of 64 scans co-added to 
increase the signal-to-noise ratio. Spectral data collection was carried out in duplicate.

Raman spectrometer: Three milliliters of oil sample was placed in a $10-\mathrm{mm}$ light path quartz cuvette (Hellma Analytics, Mulheim, Germany) and the Raman spectra were collected using a WP 1064 compact portable Raman spectrometer (Wasatch Photonics, Durham, NC, USA) (Fig. 1). The Raman unit was equipped with an Indium Gallium Arsenide (InGaAs) detector and a laser source operating at $1064 \mathrm{~nm}$. The spectra were collected from 1855 to $200 \mathrm{~cm}^{-1}$ with a resolution of $4 \mathrm{~cm}^{-1}$ and 3 scans were co-added to improve the signal-to-noise ratio of the spectrum with an integration time of $3000 \mathrm{~ms}$. A background spectrum was acquired in between every sample to eliminate the environmental variations. Spectral data were displayed in terms of scattered light by the sample and viewed using EnlightenTM software (Wasatch Photonics, Durham, NC, USA). Spectral data collection was carried out in duplicate.
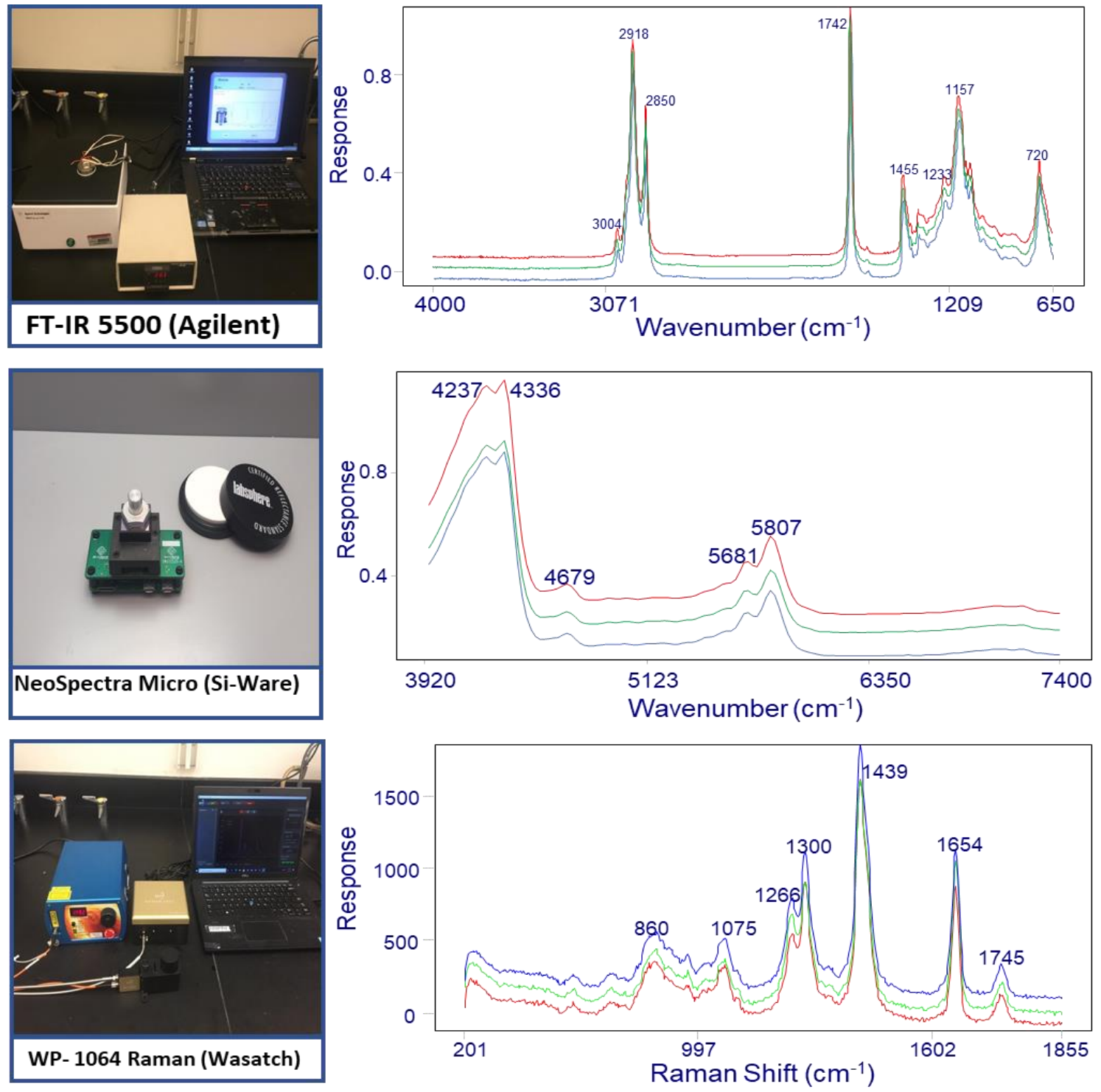

Figure 1. Commercial portable and handheld FT-MIR, FT-NIR and Raman spectrometers, and the spectra of oils obtained from them. Red line: hazelnut oil; green line: canola oil; blue line: sunflower oil 


\section{Reference method, Gas Chromatography:}

The fatty acid profile was determined using a fatty acid methyl ester (FAME) procedure (Ichihara et al., 1996) with slight modifications. A total of 100 $\mu \mathrm{L}$ oil sample was dissolved in $1 \mathrm{~mL}$ of hexane in a microcentrifuge tube; after adding $20 \mu \mathrm{L} 2 \mathrm{~N}$ potassium hydroxide in methanol, the mixture was vortexed for a minute. The microcentrifuge tube was set aside for the phase separation and $750 \mu \mathrm{L}$ of an aliquot from the upper part was removed into another microcentrifuge tube, which already has a pinch of sodium sulfate anhydrous. The tube was centrifuged at $13.2 \mathrm{rpm}$ for $5 \mathrm{~min}$ and the upper part $(\sim 500 \mu \mathrm{L})$ was transferred into a borosilicate glass vial. Samples were analyzed using an Agilent 6890 (Santa Clara, CA, USA) GC, with a flame ionization detector (FID) and an HP G1513A autosampler and a tray. Fatty acids were eluted through an HP-88 $100 \mathrm{~m}$ $\times 0.25 \mathrm{~mm} \times 0.2 \mu \mathrm{m}$ column (Agilent, Santa Clara, CA, USA), and helium was used as a carrier gas. A total of $1 \mu \mathrm{L}$ of the sample was injected with a split ratio of $20: 1$. The oven temperature was set at $110{ }^{\circ} \mathrm{C}$ for $1 \mathrm{~min}$, then increased to 220 ${ }^{\circ} \mathrm{C}\left(5^{\circ} \mathrm{C} / \mathrm{min}\right)$ and held for $15 \mathrm{~min}$. The injector temperature was $220{ }^{\circ} \mathrm{C}$, and the detector temperature was $250^{\circ} \mathrm{C}$. The identification of the fatty acids was achieved by comparing each peak's retention time against the reference standards (Supelco ${ }^{\circledR} 37$ Component FAME Mix, Sigma Aldrich, St. Louis, MO, USA). GC analyses for each sample were carried out in duplicate.

\section{Data analysis}

A multivariate data analysis software (Pirouette version 4.5, Infometrix Inc., Bothell, WA, USA) was used to analyze the spectral data.

Principle Component Analysis (PCA): Firstly, all spectra were checked using Principal Component Analysis (PCA) if any abnormalities occurred during the spectral collection or from the samples themselves. PCA is used for reducing the number of variables. It also transforms the variables that were initially measured into uncorrelated variables related to classes' similarities. In this chemometric method, the relationship among the variables and the patterns can be studied (Rodriguez-Saona et al., 2016).
Soft Independent Modeling of Class Analogy (SIMCA): It is one of the supervised pattern recognition techniques that rely on a confidence region for each class after PCA is applied. Observations are projected in each PC that decides if the observation belongs to that class or not. Because the spectra are complex, SIMCA is required for obtaining a meaningful information of the data matrix (De Maesschalck et al., 1999). More information can be found in the literature (Ballabio and Todeschini, 2009; Lavine, 2000; Wold, 1976). SIMCA was used to determine the pure samples and adulterated hazelnut oils. Known classes (hazelnut, sunflower, and canola oils) were used to create a classification algorithm to identify the correct classes $(80 \%$ of the total samples). Then, the validation data set (20\% of the samples that were not used in the classification model) was informed to evaluate the model. SIMCA was evaluated based on threedimension class projection, misclassification (if the sample was predicted in the correct class) and interclass distance (ICD).

\section{Partial Least Square Regression (PLSR):} Partial Least Square Regression (PLSR) was used to evaluate the fitness of the model using the standard error of cross-validation (SECV), standard error of prediction (SEP), coefficient of determination ( $r$ ), and outlier diagnostics. PLSR is one of the most used multivariate data analyses that is used for correlated, noisy, and for multi-X variables. For example, data obtained from FTNIR, FT-MIR, and Raman can have thousands of data points (X variable, i.e. FT-MIR - from 3500 $\mathrm{cm}^{-1}$ to $\left.800 \mathrm{~cm}^{-1}\right)$. PLSR includes the PCA features where thousands of variables can be compressed into a few latent variables called as factors, predictors, or components. Detailed information for PLSR can be found in the literature (Brereton, 2000; Haaland and Thomas, 1988; Jong, 1993; Wold et al., 2001). Samples with large residuals indicating the samples with structure do not fit in the model, and high leverage indicates the sample or variable have very much impact on the calibration model were considered as outliers (not shown in the data). 


\section{RESULTS AND DISCUSSION}

Table 1 summarizes the fatty acid profile of hazelnut (HO), sunflower (SFO), and canola (CO) oils. Five of 36 commercial hazelnut samples were suspected of being adulterated with different oils because the fatty acid (FA) profile deviated from HO's FA profile. Suspected samples generally consisted of a low amount of oleic, and a high amount of linoleic and linolenic acids. An example of pure hazelnut oil and suspected hazelnut oil GC chromatogram was shown in Fig 2.

Table 1. Summary of fatty acid profiles of hazelnut, sunflower, and canola oils

\begin{tabular}{|c|c|c|c|c|c|c|}
\hline & $\mathrm{n}$ & $16: 0$ & 18:0 & $18: 1$ & $18: 2$ & $18: 3$ \\
\hline Hazelnut oil & 31 & $5.77 \pm 0.25$ & $2.41 \pm 0.18$ & $76.72 \pm 4.33$ & $14.56 \pm 4.17$ & $0.27 \pm 0.11$ \\
\hline $\begin{array}{l}\text { Suspected } \\
\text { hazelnut oil }\end{array}$ & 5 & $5.91 \pm 0.22$ & $2.61 \pm 0.34$ & $60.36 \pm 5.10$ & $30.07 \pm 5.70$ & $1.59 \pm 0.73$ \\
\hline $\begin{array}{l}\text { Sunflower } \\
\text { oil }\end{array}$ & 6 & $4.79 \pm 0.12$ & $3.34 \pm 0.02$ & $62.15 \pm 0.97$ & $28.19 \pm 0.96$ & $0.42 \pm 0.01$ \\
\hline Canola oil & 6 & $4.29 \pm 0.07$ & $1.93 \pm 0.11$ & $63.97 \pm 0.23$ & $20.26 \pm 0.81$ & $7.04 \pm 0.47$ \\
\hline
\end{tabular}

16:0-palmitic acid; 18:0-stearic acid; 18:1-oleic acid; 18:2-linoleic acid: 18:3-linolenic acid: n-number of samples

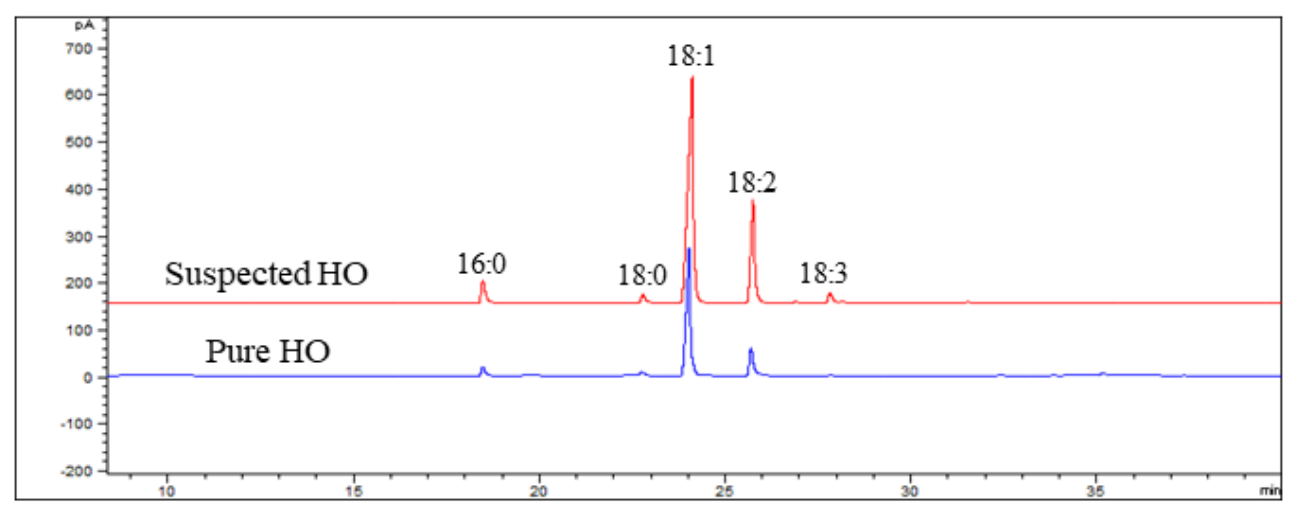

Figure 2. Chromatograms obtained from gas chromatography of suspected hazelnut oil and pure hazelnut oil

\section{PCA \& SIMCA results - FT-NIR Spectra}

Because the NIR spectra were complex and overlapping peaks would be marked and large variations of baseline make the interpretation difficult, the spectra were $2^{\text {nd }}$ derivative and smooth transformed (with second order polynominal filter with a 35-point window) to improve spectral characteristics. PCA projection was shown in Fig 3A. PCA was used to determine if any sample was an outlier, including suspected samples, and any sample had impurities. Pure hazelnut oils, canola oils, sunflower oils, and suspected oils were clustered distinctly. Modeling power, which expresses how well the principal components discriminate different oils, for classification was shown in Fig 3B. The most important absorption peaks were found at 4434 $\mathrm{cm}^{-1}\left(-\mathrm{CH}_{3}\right.$ combination), $5464\left(-\mathrm{CH}=\mathrm{CH}-1^{\text {st }}\right.$ overtone), $5980 \mathrm{~cm}^{-1}\left(-\mathrm{CH}_{3} 1^{\text {st }}\right.$ overtone), and $6743 \mathrm{~cm}^{-1} \quad\left(-\mathrm{CH}_{2} \quad 1^{\text {st }}\right.$ overtone $)$. Peak identifications were made based on the literature (Hourant et al., 2000). SIMCA was used to create 
an algorithm for the classification of the oils. SIMCA 3D class projection was shown in Fig 3C. Hazelnut oils, sunflower oils, and canola oils were clustered distinctly. The most important absorption peaks were found at $4189 \mathrm{~cm}^{-1}\left(-\mathrm{CH}_{2}\right.$ combination), $4545 \quad \mathrm{~cm}^{-1} \quad(-\mathrm{CH}=\mathrm{CH}-$ combination), $5612 \mathrm{~cm}^{-1}$ (-CH $2^{\text {nd }}$ overtone $), 6238$ $\mathrm{cm}^{-1}\left(-\mathrm{CH}_{2} 1^{\text {st }}\right.$ overtone $), 6964 \mathrm{~cm}^{-1}\left(\mathrm{O}-\mathrm{H} 1^{\text {st }}\right.$ overtone). Interclass distances (ICD) describe the similarities and/or dissimilarities between the classes, and it is generally accepted that classes show differentiation when the ICD is $>3$ (Massart et al., 2003). ICD of the samples were over 26.3 which indicates FT-NIR discriminates the oils perfectly. Besides the ICD values, the SIMCA classification model had no misclassification, and the prediction performance of the model revealed $100 \%$ specificity and sensitivity. Handheld FT-NIR spectrometer combined with multivariate analysis showed that it could be used as an alternative method to detect hazelnut oil adulteration with fixed oils. Basri and others evaluated the detection of lard adulteration in palm oil using a portable microNIR unit (Basri et al., 2017). The researchers have classified the pure samples from the adulterated samples with a $40 \%$ sensitivity and $100 \%$ specificity.
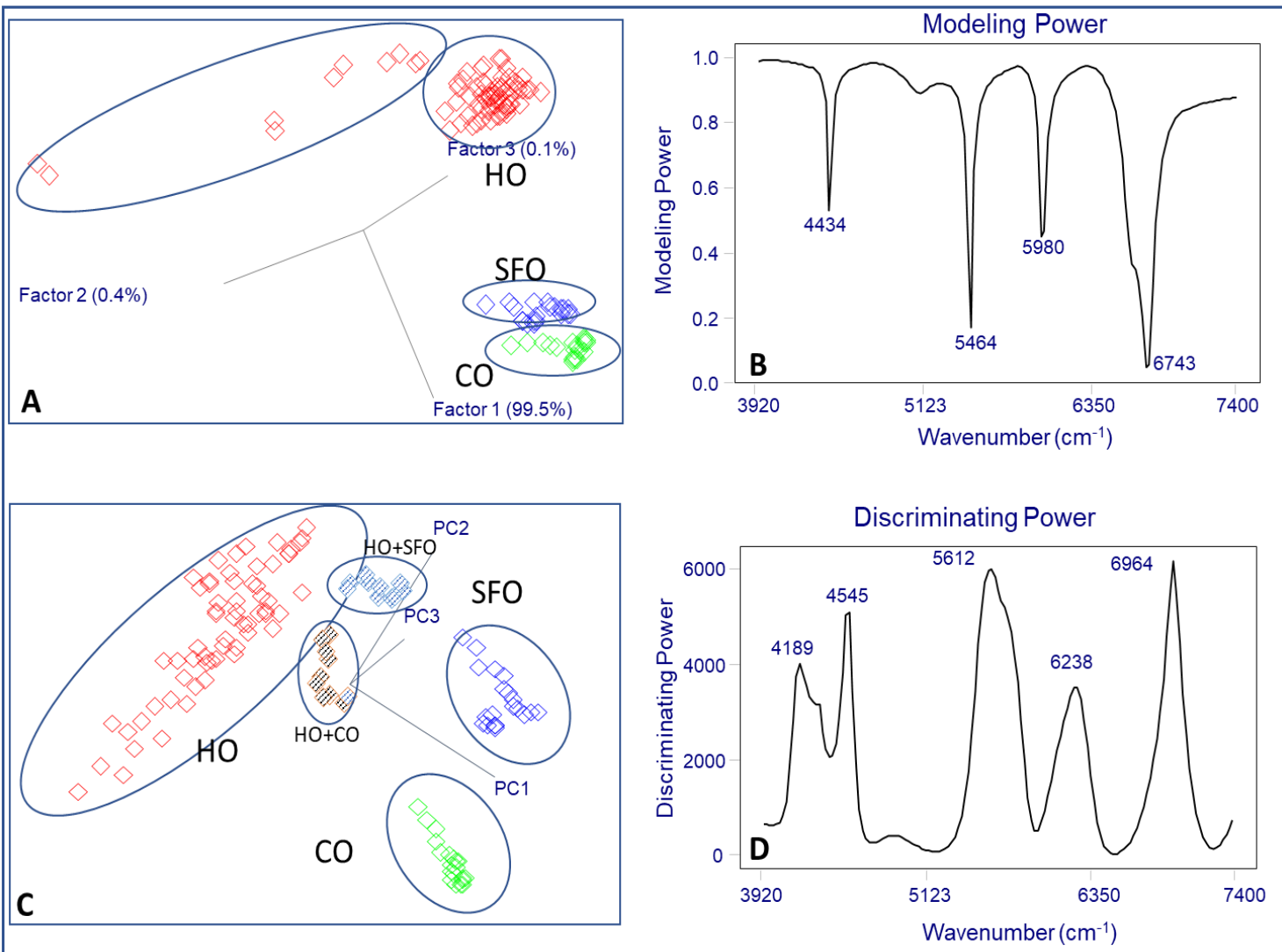

Figure 3. Principal Component Analysis of FT-NIR spectra (A), modeling power obtained from PCA (B), soft independent modelling of class analogy $(C)$, and discriminating power obtained from SIMCA (D). HO: hazelnut oil; CO: canola oil; SFO: sunflower oil

PCA \& SIMCA - FT-MIR Spectra

Before the PCA and SIMCA analysis, spectra were $2^{\text {nd }}$ derivative and smooth transformed (second-order poly-nominal filter with a 35-point window). The oils were discriminated based on
PCA analysis (Fig 4A). Associated bands were found around $2950-2800 \mathrm{~cm}^{-1}\left(\mathrm{CH}_{2}\right.$ symmetric or asymmetric stretching), $1800-1700 \mathrm{~cm}^{-1}$ (C-O stretching esters of fatty acids), $1450-1350$ (C-H bending), $1200-1000 \mathrm{~cm}^{-1}$ (C-O, C-C stretching) 
(Fig 4B). The peaks assignment was made based on the literature (Rodriguez-Saona et al., 2016). After suspected samples were excluded from the data matrix, SIMCA analysis was performed (Fig 4C). Based on the discriminating power, the peaks at $2875 \mathrm{~cm}^{-1}$ associated with -C-H $\left(\mathrm{CH}_{2}\right)$ stretching, 1753 and $1707 \mathrm{~cm}^{-1}$ associated with $\mathrm{C}=\mathrm{O}$ ester stretching of fatty acids (Fig 4D). These peaks were associated with saturated and unsaturated fatty acid distribution of the oils. For example, sunflower oil has more stearic acid among the samples, while canola oil has more linolenic acid. These differences in the fatty acid distribution of the oils were detected by the spectra. The difference between PCA modeling power and SIMCA discriminating power was due to the contribution of the suspected samples to the PCA model. The impurities of the suspected samples had some effects on the PCA model. In our SIMCA model, the ICD values were at least 17.5 between the samples, which indicates that portable FT-MIR spectrometer discriminated the samples very distinctly. Similar to the FT-NIR SIMCA model, the FT-MIR SIMCA model had no misclassification and $\% 100$ specificity and sensitivity were observed. Overall, the portable FT-MIR spectrometer showed that it could be used for routine analysis for the quality control of the hazelnut oil.
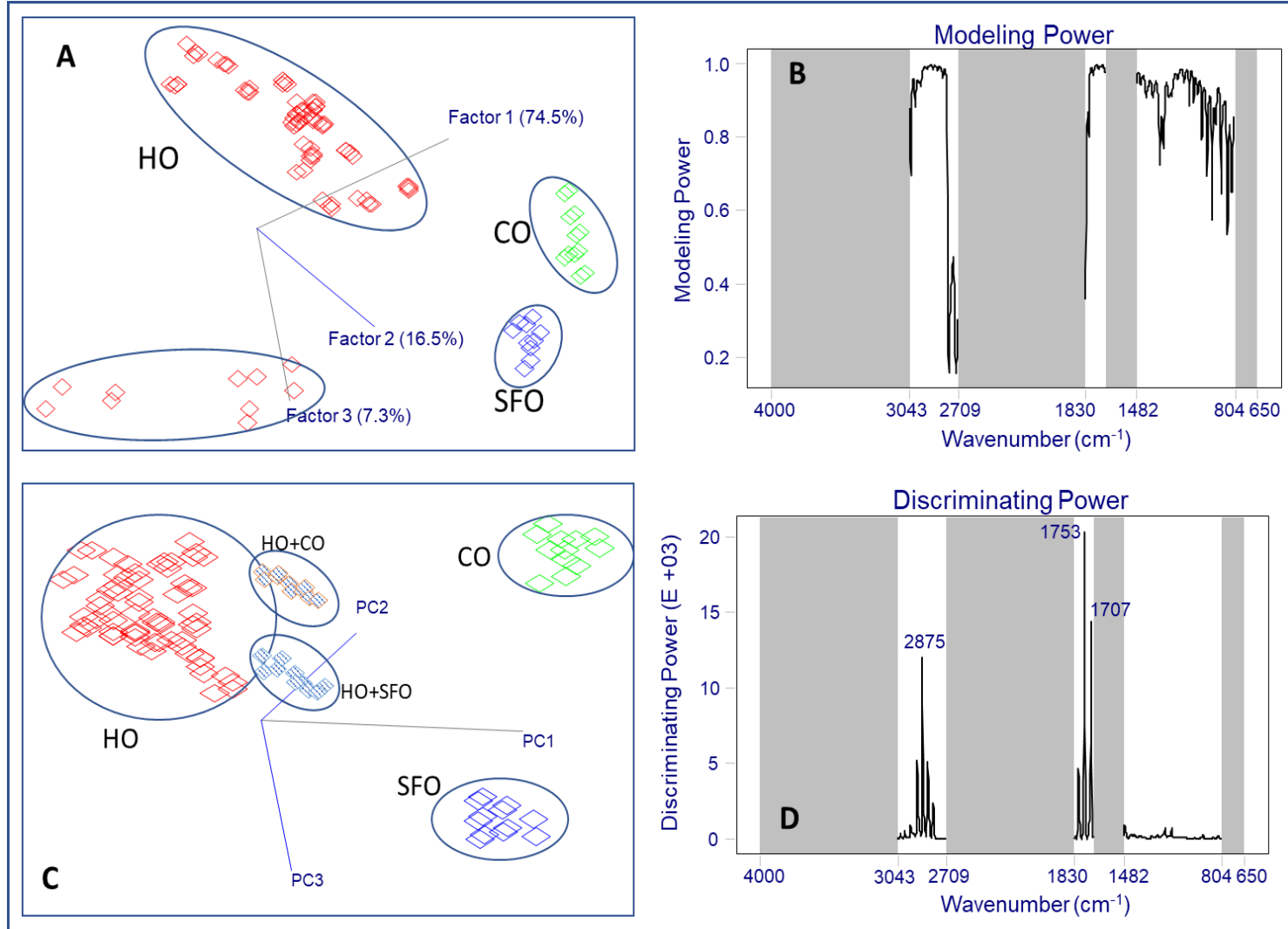

Figure 4. Principal Component Analysis of FT-MIR spectra (A), modeling power obtained from PCA (B), soft independent modelling of class analogy (C), and discriminating power obtained from SIMCA (D). HO: hazelnut oil; CO: canola oil; SFO: sunflower oil

PCA \& SIMCA results - Raman Spectra

Before the PCA and SIMCA analysis, Raman spectra were $2^{\text {nd }}$ derivative and smooth transformed (second-order poly-nominal filter with a 35-point window) to reduce the effects of noise on the models. Based on the PCA model (Fig 5A), all the samples were discriminated. Associated bands to the model (Fig 5B) were 
found around $1288 \mathrm{~cm}^{-1}$ (twisting $-\mathrm{CH}_{2}$ ), $1447 \mathrm{~cm}$ ${ }^{1}$ (bending - $\mathrm{CH}_{2}$ ), and $1657 \mathrm{~cm}^{-1}$ (stretching cis-R$\mathrm{HC}=\mathrm{CH}-\mathrm{R})$. After suspected samples were excluded from the data matrix, SIMCA analysis was performed (Fig 5C). SIMCA provided very distinct clusters for the groups. Discriminating power of the SIMCA model (Fig 5D) indicated that the peak at $1439 \mathrm{~cm}^{-1}$ was associated with -C$\mathrm{H}$ bending $\left(-\mathrm{CH}_{2}\right), 1650$ and $1667 \mathrm{~cm}^{-1}$ were related to $\mathrm{C}=\mathrm{C}$ stretching $($ cis- $\mathrm{R}-\mathrm{HC}=\mathrm{CH}-\mathrm{R})$ from polyunsaturated fatty acids. The peak assignments were made based on the literature (Aykas et al., 2020c). The SIMCA model showed great potential of its use in detecting the adulteration of hazelnut oil with fixed oils since the ICD values were over 5.0, indicating portable Raman spectrometer discriminated the samples distinctly. As mentioned before, those bands are related to monounsaturated and polyunsaturated fatty acids, and a positive correlation can be observed as an increase in the band intensity increases the percentage of unsaturated fatty acids in the oils.
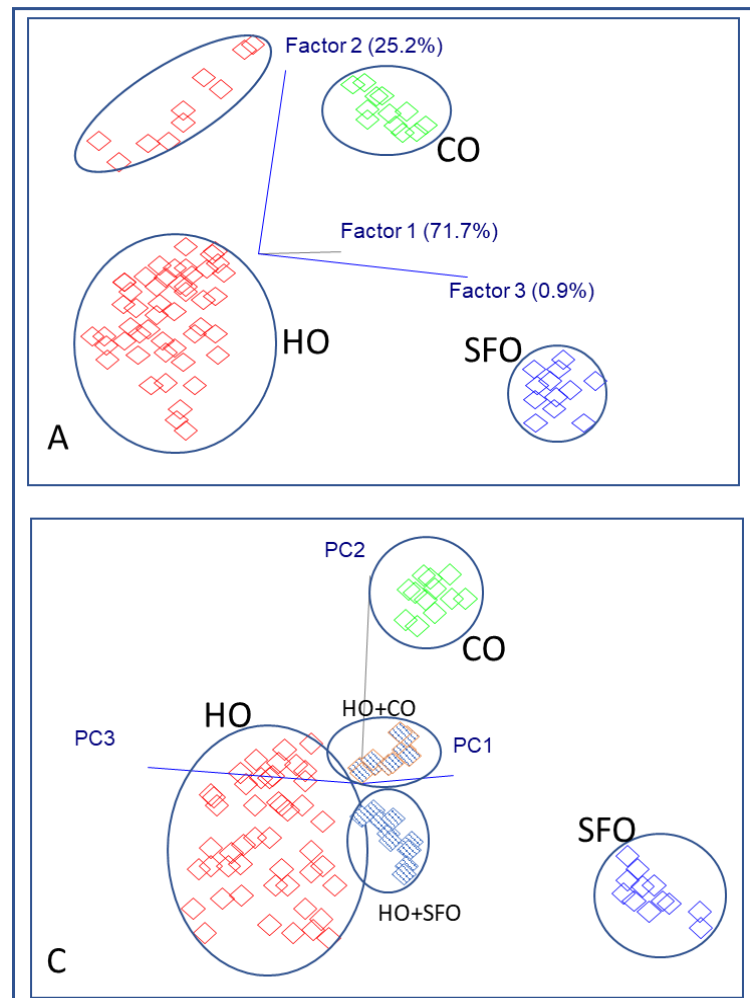
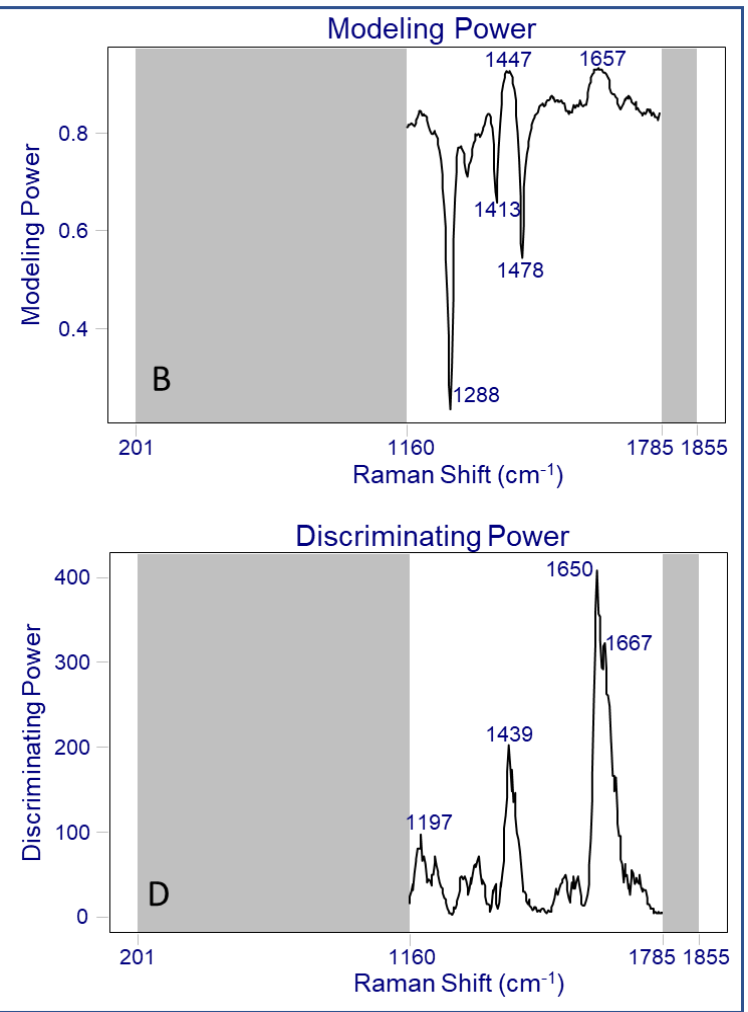

Figure 5. Principal Component Analysis of Raman spectra (A), modeling power obtained from PCA (B), soft independent modelling of class analogy (C), and discriminating power obtained from SIMCA (D). HO: hazelnut oil; CO: canola oil; SFO: sunflower oil

Comparing the three units, the Raman spectrometer was weaker than FT-NIR, and FTMIR as ICD values of the classes were lower than the values obtained from FT-NIR and FT-MIR. Best results were obtained from the handheld FTNIR spectrometer. Still, the Raman spectrometer has the potential for analysis for quality control purposes.

\section{Partial Least Squares Regression}

Table 2 shows the performance of predicting models developed using portable FT-NIR, FTMIR, and Raman spectrometers for predicting fatty acids levels and adulterant levels. In most cases, using a high number of factors improves the prediction performances; however, it may include noise or irrelevant components that can cause overfitting the model. Similarly, using fewer 
factors than the optimal number can cause underfitting that results from incorporating less variance than needed (Abdi, 2010). The optimum factors for our predictive models were between two to five. All generated predictive models had very good performances in terms of high $r_{\text {val }}$ and low SECV values. To evaluate the portable units' performances, spectra were collected under the same conditions for the samples purchased from the markets. Validation models showed that a similar or slightly lower performance than calibration models. Overall, among the three units, the best performance was obtained from the portable FT-MIR spectrometer. Handheld FT-NIR spectrometer showed the least performance for the predicting models. For all prediction models, FT-MIR and Raman spectrometer performances were excellent because the $r_{v a l}$, when it is over 0.90 , indicated the prediction level was excellent (Shenk and Westerhaus, 1996; Urbano Cuadrado et al., 2005). FT-NIR also showed excellent performance for the prediction models except for stearic acid as it was 0.86; however, it still shows a very good performance. Similarly, Aykas and others reported that the portable FT-MIR unit has superior performances over the portable Raman unit on the prediction of fatty acid composition in olive oil samples (Aykas et al., 2020b).

Table 2. Statistical performance of the prediction models developed using FT-NIR, FT-MIR, and Raman spectrometers for predicting fatty acid and adulteration levels of hazelnut oil

\begin{tabular}{|c|c|c|c|c|c|c|c|c|c|c|}
\hline \multirow{2}{*}{ Unit } & \multirow{2}{*}{ Parameter } & \multicolumn{5}{|c|}{ Calibration model } & \multicolumn{4}{|c|}{ Validation model } \\
\hline & & Rangea & $\mathrm{Nb}$ & $\mathrm{Fc}$ & SECVd & $\mathrm{r}_{\mathrm{cal}} \mathrm{e}^{\mathrm{e}}$ & Range & $\mathrm{N}$ & SEPf & $\mathrm{r}_{\mathrm{val}} \mathrm{I}^{\mathrm{g}}$ \\
\hline \multirow{7}{*}{ FT-NIR } & $16: 0$ & $4.1-6.3$ & 54 & 4 & 0.09 & 0.95 & $4.3-6.1$ & 12 & 0.14 & 0.92 \\
\hline & 18:0 & $1.8-3.3$ & 51 & 5 & 0.11 & 0.90 & $1.9-3.2$ & 12 & 0.13 & 0.86 \\
\hline & $18: 1$ & $55-78$ & 54 & 5 & 1.42 & 0.97 & $58-76$ & 12 & 1.64 & 0.95 \\
\hline & $18: 2$ & $13-35$ & 54 & 5 & 1.31 & 0.97 & $16-32$ & 12 & 1.49 & 0.96 \\
\hline & $18: 3$ & $0.1-7.4$ & 52 & 4 & 0.13 & 0.93 & $0.4-6.5$ & 12 & 0.21 & 0.93 \\
\hline & SFO & $0-25$ & 12 & 2 & 1.61 & 0.94 & $5.0-20.0$ & 4 & 1.73 & 0.93 \\
\hline & $\mathrm{CAO}$ & $0-25$ & 12 & 3 & 1.42 & 0.95 & $5.0-20.0$ & 4 & 1.62 & 0.93 \\
\hline \multirow{7}{*}{ FT-MIR } & $16: 0$ & $4.1-6.3$ & 54 & 4 & 0.05 & 0.98 & $4.3-6.1$ & 12 & 0.07 & 0.97 \\
\hline & 18:0 & $1.8-3.3$ & 50 & 4 & 0.03 & 0.99 & $1.9-3.2$ & 12 & 0.07 & 0.96 \\
\hline & $18: 1$ & $55-78$ & 53 & 3 & 0.28 & 1 & $58-76$ & 12 & 0.72 & 0.99 \\
\hline & $18: 2$ & $13-35$ & 53 & 4 & 0.85 & 0.99 & $16-32$ & 12 & 0.94 & 0.98 \\
\hline & $18: 3$ & $0.1-7.4$ & 52 & 5 & 0.11 & 0.98 & $0.4-6.5$ & 12 & 0.19 & 0.96 \\
\hline & SFO & $0-25$ & 12 & 5 & 1.12 & 0.96 & $5.0-20.0$ & 4 & 1.33 & 0.95 \\
\hline & $\mathrm{CAO}$ & $0-25$ & 12 & 5 & 1.24 & 0.96 & $5.0-20.0$ & 4 & 1.32 & 0.95 \\
\hline \multirow{7}{*}{ Raman } & $16: 0$ & $4.1-6.3$ & 54 & 4 & 0.18 & 0.98 & $4.3-6.1$ & 12 & 0.25 & 0.96 \\
\hline & 18:0 & $1.8-3.3$ & 51 & 3 & 0.06 & 0.97 & $1.9-3.2$ & 12 & 0.08 & 0.95 \\
\hline & $18: 1$ & $55-78$ & 53 & 2 & 1.23 & 0.97 & $58-76$ & 12 & 1.25 & 0.97 \\
\hline & $18: 2$ & $13-35$ & 53 & 2 & 1.22 & 0.97 & $16-32$ & 12 & 1.25 & 0.97 \\
\hline & $18: 3$ & $0.1-7.4$ & 52 & 5 & 0.11 & 0.96 & $0.4-6.5$ & 12 & 0.18 & 0.95 \\
\hline & SFO & $0-25$ & 12 & 2 & 1.22 & 0.94 & $5.0-20.0$ & 4 & 1.42 & 0.93 \\
\hline & CAO & $0-25$ & 12 & 3 & 1.31 & 0.96 & $5.0-20.0$ & 4 & 1.63 & 0.94 \\
\hline
\end{tabular}

${ }^{a}$ The unit of the range is \%. ${ }^{b}$ Number of samples used in calibration models. ${ }^{c}$ The number of factors. dStandard

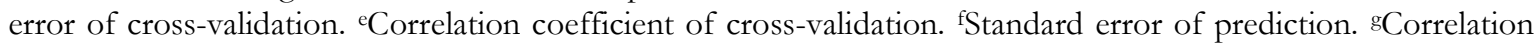
coefficient of prediction for external validation. 


\section{CONCLUSIONS}

In this study, sunflower and canola oil adulteration in hazelnut oil were aimed to be determined by portable FT-NIR, FT-MIR, and Raman spectrometers. SIMCA and PLSR models were developed to authenticate pure hazelnut oils and predict fatty acid and adulterant levels. Portable vibrational spectroscopic units, combined with chemometrics, provided rapid $(\sim 10 \mathrm{~s})$, non-invasive, and reliable determination of adulterated hazelnut oils with sunflower and canola oils. We observed that five out of 36 commercial hazelnut oils on the market were suspected as adulterated based on our portable units and GC results. FT-MIR spectrometer showed slightly better performance than FT-NIR and Raman spectrometers. Vibrational spectroscopy techniques may detect sunflower and canola oil adulterations on hazelnut oils as low as $5 \%$. These units can be used as an alternative method to traditional methods and provide the oil industry and government agencies an easy, non-invasive method to detect adulterations in hazelnut oils.

\section{ACKNOWLEDGMENTS}

Authors would like to thank Prof. Luis E. Rodriguez-Saona (The Ohio State University, Department of Food Science and Technology) for his technical support rendered during this study. This research received no external funding.

\section{CONFLICTS OF INTEREST}

Authors declare that they have no conflict of interest. This article does not contain any studies with human or animal subjects.

\section{AUTHORS' CONTRIBUTIONS}

A.M: Formal analysis, methodology, data curation, original draft; D.P.A: Formal analysis, methodology, data curation, review and editing.

\section{REFERENCES}

Abdi, H. (2010). Partial least squares regression and projection on latent structure regression (PLS Regression). Wiley Interdisciplinary Reviews: Computational Statistics, 2(1), 97-106. https://doi.org/10.1002/wics.51
Akkaya, M. R. (2018). Prediction of fatty acid composition of sunflower seeds by near-infrared reflectance spectroscopy. Journal of Food Science and Technology, 55(6), 2318-2325. https://doi.org/ 10.1007/s13197-018-3150-x

Aykas, D. P., Ball, C., Sia, A., Zhu, K., Shotts, M. L., Schmenk, A., \& Rodriguez-Saona, L. (2020a). In-situ screening of soybean quality with a novel handheld near-infrared sensor. Sensors (Switzerland), 20(21), 1-19. https://doi.org/ $10.3390 / \mathrm{s} 20216283$

Aykas, D. P., Karaman, A. D., Keser, B., \& Rodriguez-Saona, L. (2020b). Non-targeted authentication approach for extra virgin olive oil. Foods, 9(2), 1-17. https://doi.org/10.3390/ foods 9020221

Aykas, D. P., \& Menevseoglu, A. (2021). A rapid method to detect green pea and peanut adulteration in pistachio by using portable FTMIR and FT-NIR spectroscopy combined with chemometrics. Food Control, 121. https://doi.org/ 10.1016/j.foodcont.2020.107670

Aykas, D. P., Shotts, M.-L., \& Rodriguez-Saona, L. E. (2020c). Authentication of commercial honeys based on Raman fingerprinting and pattern recognition analysis. Food Control, 117(May), 107346. https://doi.org/10.1016/ j.foodcont.2020.107346

Ayvaz, H., \& Rodriguez-Saona, L. E. (2015). Application of handheld and portable spectrometers for screening acrylamide content in commercial potato chips. Food Chemistry, 174, 154-162. https://doi.org/10.1016/j.foodchem. 2014.11.001

Ayvaz, H., Sierra-Cadavid, A., Aykas, D. P., Mulqueeney, B., Sullivan, S., \& Rodriguez-Saona, L. E. (2016). Monitoring multicomponent quality traits in tomato juice using portable mid-infrared (MIR) spectroscopy and multivariate analysis. Food Control, 66, 79-86. https://doi.org/10.1016/j.foodcont.2016.01.031

Ballabio, D., \& Todeschini, R. (2009). Infrared Spectroscopy for Food Quality Analysis and Control Multivariate Classifi cation for Qualitative Analysis. In D.-W. Sun (Ed.), Infrared 
Spectroscopy for Food Quality Analysis and Control (1st ed., pp. 83-104). Burlington, MA: Elsevier.

Basri, K. N., Hussain, M. N., Bakar, J., Sharif, Z., Khir, M. F. A., \& Zoolfakar, A. S. (2017). Classification and quantification of palm oil adulteration via portable NIR spectroscopy. Spectrochimica Acta - Part A: Molecular and Biomolecular Spectroscopy, 173, 335-342. https://doi.org/10.1016/j.saa.2016.09.028

Benitez-Sánchez, P. L., León-Camacho, M., \& Aparicio, R. (2003). A comprehensive study of hazelnut oil composition with comparisons to other vegetable oils, particularly olive oil. European Food Research and Technology, 218(1), 13-19. https://doi.org/10.1007/s00217-003-0766-4

Brereton, R. G. (2000). Introduction to multivariate calibration in analytical chemistry. Analyst, 125(11), 2125-2154. https://doi.org/ 10.1039/b003805i

Celenk, V. U., Argon, Z. U., \& Gumus, Z. P. (2020). Cold pressed hazelnut (Corylus avellana) oil. In M. F. Ramadan (Ed.), Cold Pressed Oils. https://doi.org/10.1016/b978-0-12-8181881.00020-7

Cercaci, L., Rodriguez-Estrada, M. T., \& Lercker, G. (2003). Solid-phase extraction-thin-layer chromatography-gas chromatography method for the detection of hazelnut oil in olive oils by determination of esterified sterols. Journal of Chromatography A, 985(1-2), 211-220. https://doi.org/ 10.1016/S0021-9673(02)013973

Christy, A. A., Kasemsumran, S., Du, Y., \& Ozaki, Y. (2004). The detection and quantification of adulteration in olive oil by near-infrared spectroscopy and chemometrics. Analytical Sciences, 20(6), 935-940. https://doi.org/10.2116/ analsci.20.935

De Maesschalck, R., Candolfi, A., Massart, D. L., \& Heuerding, S. (1999). Decision criteria for soft independent modelling of class analogy applied to near infrared data. Chemometrics and Intelligent Laboratory Systems, 47(1), 65-77. https://doi.org/10.1016/S0169-7439(98)001592 
Findigin Yeri. Retrieved from https://arastirma.tarimorman.gov.tr/findik/Sayf alar/Detay.aspx?SayfaId $=29$

Mariani, C., Bellan, G., Lestini, E., \& Aparicio, R. (2006). The detection of the presence of hazelnut oil in olive oil by free and esterified sterols. European Food Research and Technology, 223(5), 655661. https://doi.org/10.1007/s00217-005-0249$\mathrm{x}$

Massart, D. L., Vandeginste, B. G. M., Deming, S. N., Michotte, Y., \& Kaufman, L. (2003). Chemometrics: a textbook (fifth). Amsterdam, Netherlands: Elsevier B.V.

Mcgrath, T. F., Haughey, S. A., Islam, M., \& Elliott, C. T. (2020). The Potential of Handheld Near Infrared Spectroscopy to detect food adulteration: Results of a global, multi-instrument inter-laboratory study. Food Chemistry, 128718. https://doi.org/10.1016/j.foodchem.2020.12871 8

Menevseoglu, A. (2021) Non-destructive detection of sesame oil adulteration by portable FT-NIR, FT-MIR, and Raman spectrometers combined with chemometrics. JOTCS $A$, 8(3), 775-786.

https://doi.org/10.18596/jotcsa.940424

Menevseoglu, A., Aykas, D. P., \& Adal, E. (2021). Non-targeted approach to detect green pea and peanut adulteration in pistachio by using portable FT-IR, and UV-Vis spectroscopy. Journal of Food Measurement and Characterization. https://doi.org/ 10.1007/s11694-020-00710-y

Miaw, C. S. W., Sena, M. M., Souza, S. V. C. de, Ruisanchez, I., \& Callao, M. P. (2018). Variable selection for multivariate classification aiming to detect individual adulterants and their blends in grape nectars. Talanta, 190(July), 55-61. https://doi.org/10.1016/j.talanta.2018.07.078

Mossoba, M. M., Srigley, C. T., Farris, S., Kramer, J. K. G., Chirtel, S., \& Rader, J. (2014). Evaluation of the Performance of a Portable Mid-Infrared Analyzer for the Rapid Determination of Total Trans Fat in Fast Food. JAOCS, Journal of the American Oil Chemists' Society, 91(10), 1651-1663. https://doi.org/10.1007/s11746-014-2521-3
Ozen, B. F., \& Mauer, L. J. (2002). Detection of hazelnut oil adulteration using FT-IR spectroscopy. Journal of Agricultural and Food Chemistry, 50, 3898-3901. https://doi.org/ 10.1021/jf0201834

Pei, X., Tandon, A., Alldrick, A., Giorgi, L., Huang, W., \& Yang, R. (2011). The China melamine milk scandal and its implications for food safety regulation. Food Policy, 36(3), 412-420. https://doi.org/10.1016/j.foodpol.2011.03.008

Platteau, C., De Loose, M., De Meulenaer, B., \& Taverniers, I. (2011). Quantitative detection of hazelnut (Corylus avellana) in cookies: ELISA versus real-time PCR. Journal of Agricultural and Food Chemistry, 59(21), 11395-11402. https://doi.org/10.1021/jf202167b

Quintanilla-Casas, B., Strocchi, G., Bustamante, J., Torres-Cobos, B., Guardiola, F., Moreda, W., ... Vichi, S. (2021). Large-scale evaluation of shotgun triacylglycerol profiling for the fast detection of olive oil adulteration. Food Control, 123. https://doi.org/10.1016/j.foodcont. 2020.107851

Rodriguez-Saona, L., Aykas, D. P., Borba, K. R., \& Urtubia, A. (2020). Miniaturization of optical sensors and their potential for high-throughput screening of foods. Current Opinion in Food Science, 31, 136-150. https://doi.org/10.1016/ j.cofs.2020.04.008

Rodriguez-Saona, L. E., Giusti, M. M., \& Shotts, M. (2016a). Advances in infrared spectroscopy for food authenticity testing. In Advances in Food Authenticity Testing. https://doi.org/10.1016/ B978-0-08-100220-9.00004-7

Shenk, J. S., \& Westerhaus, M. O. (1996). Calibration the ISI way. Near infrared spectroscopy: The future waves. Chichester, UK: NIR Publications.

Shotts, M. L., Plans Pujolras, M., Rossell, C., \& Rodriguez-Saona, L. (2018). Authentication of indigenous flours (Quinoa, Amaranth and kañiwa) from the Andean region using a portable ATR-Infrared device in combination with pattern recognition analysis. Journal of Cereal Science, 82, 65-72. https://doi.org/10.1016/j.jcs.2018.04.005 
Şisik Ogras, Ş., Kaban, G., \& Kaya, M. (2018). Ham ve Rafine Findık Yağlarının Uçucu Bileşikleri ve Yağ Asidi Kompozisyonu. Atatürk Üniversitesi Ziraat Fakültesi Dergisi, 9(2), 104-110. https://doi.org/10.17097/ataunizfd.392547

Sun, Y., Yuan, M., Liu, X., Su, M., Wang, L., Zeng, Y., .. Nie, L. (2020). Comparative analysis of rapid quality evaluation of Salvia miltiorrhiza (Danshen) with Fourier transform near-infrared spectrometer and portable near-infrared spectrometer. Microchemical Journal, 159(August), 105492. https://doi.org/10.1016/j.microc.2020. 105492

Turan, A. (2018). Effect of drying methods on fatty acid profile and oil oxidation of hazelnut oil during storage. European Food Research and Technology, 244(12), 2181-2190. https://doi.org/ 10.1007/s00217-018-3128-y

Urbano Cuadrado, M., Luque De Castro, M. D., Pérez Juan, P. M., \& Gómez-Nieto, M. A. (2005). Comparison and joint use of near infrared spectroscopy and Fourier transform mid infrared spectroscopy for the determination of wine parameters. Talanta, 66(1), 218-224. https://doi.org/10.1016/j.talanta.2004.11.011
Wold, S. (1976). Pattern recognition by means of disjoint principal components models. Pattern Recognition, 8(3), 127-139. https://doi.org/ 10.1016/0031-3203(76)90014-5

Wold, S., Sjöström, M., \& Eriksson, L. (2001). PLS-regression: A basic tool of chemometrics. Chemometrics and Intelligent Laboratory Systems, 58(2), 109-130. https://doi.org/10.1016/S01697439(01)00155-1

Zabaras, D., \& Gordon, M. H. (2004). Detection of pressed hazelnut oil in virgin olive oil by analysis of polar components: Improvement and validation of the method. Food Chemistry, 84(3), 475-483. https://doi.org/10.1016/j.foodchem. 2003.07.029

Zambiazi, R. U. I. C., Przybylski, R., Zambiazi, M. W., \& Mendonça, C. B. (2007). Fatty Acid Composition of Vegetable Oils and Fats. Boletim Do Centro de Pesquisa de Processamento de Alimentos, 25(1), 111-120. 